\title{
Induction of labor in breech presentations at term : a retrospective observational study
}

\section{Macharey, Georg}

2016-03

Macharey , G , Ulander , V-M , Heinonen , S , Kostev , K , Nuutila , M \& Vaisanen-Tommiska , M 2016 , ' Induction of labor in breech presentations at term : a retrospective observational study ' , Archives of Gynecology and Obstetrics , vol. 293 , no. 3 , pp. 549-555 . https://doi.org/10.1007/s00404-015-

http://hdl.handle.net/10138/161263

https://doi.org/10.1007/s00404-015-3853-4

publishedVersion

Downloaded from Helda, University of Helsinki institutional repository.

This is an electronic reprint of the original article.

This reprint may differ from the original in pagination and typographic detail.

Please cite the original version. 


\title{
Induction of labor in breech presentations at term: a retrospective observational study
}

\author{
Georg Macharey ${ }^{1}$ - Veli-Matti Ulander ${ }^{1} \cdot$ Seppo Heinonen $^{1} \cdot$ Karel Kostev $^{2}$ • \\ Mika Nuutila $^{1} \cdot$ Mervi Väisänen-Tommiska ${ }^{1}$
}

Received: 28 April 2015/ Accepted: 14 August 2015/Published online: 28 August 2015

(C) Springer-Verlag Berlin Heidelberg 2015

\begin{abstract}
Objective The aim of this study is to evaluate whether induction of breech delivery at term is feasible and safe for mother and child compared with spontaneous vaginal breech delivery.

Study design A total of 268 singleton term breech deliveries with an attempted vaginal delivery were identified in a single-center retrospective observational study. Out of these, 73 cases had an induction of labor for various medical and obstetric reasons and were compared to 195 spontaneous singleton breech deliveries. The main outcome measure was the mode of delivery. Secondary outcomes included maternal and neonatal morbidity and mortality.

Results The vaginal delivery rate in the induction group was $64.4 \%$ compared with $80 \%$ in the spontaneous delivery group. No statistical differences were observed between the two delivery groups regarding neonatal and maternal morbidity and mortality.

Conclusions The vaginal delivery rate was significantly lower in induced than in spontaneous breech deliveries. The neonatal and maternal morbidity and mortality rates were similar implying that induction in breech delivery is an option and it is time for clinical reappraisal.
\end{abstract}

Georg Macharey

georg.macharey@hus.fi

1 Department of Obstetrics and Gynecology, Helsinki University and Helsinki University Central Hospital, Haartmaninkatu 2, 00029 Helsinki, Finland

2 Department of Health and Social Affairs, Fresenius University of Applied Sciences, Idstein, Germany
Keywords Breech presentation - Mode of delivery . Cesarean · Mortality · Morbidity · Induction

\section{Introduction}

Cesarean section rates are increasing worldwide. Cesarean delivery is associated with short- and long-term risks and consequences, such as surgical complications, admissions to intensive care units, and higher costs, compared with vaginal delivery [1-3]. Breech presentation is one of the main indications for primary cesareans, covering up to $17 \%$ of all cases $[4,5]$. The safety of vaginal breech delivery has been debated regularly over the last decades. The term breech trial by Hannah ME conducted in 2000 is one of the reasons for this [6], as the trial recommended delivery by cesarean section for all breech presentations [6].

Many other studies have shown since then that spontaneous vaginal breech delivery is in the long-term perspective safe for both the mother and child if women are selected to trial of labor carefully and labor management takes place in an appropriate obstetric setting [4, 7-13]. The British, Canadian, French and German associations of obstetricians and gynecologists have defined guidelines to determine under which circumstances breech presentation is recommended for vaginal delivery [14-17].

Induction of labor in vertex position is a common obstetric procedure since induction rates of approximately $20 \%$ of all pregnancies in low perinatal risk countries have been reported [18, 19]. In contrast, induction of labor in breech presentation is a bit controversial and rarely practiced. Only few studies with small sample sizes $(N=13-53)$ have been published in the English literature [20-22]. These studies, albeit few have shown favorable 
maternal and neonatal outcomes in breech delivery inductions at term.

International guidelines for breech delivery are discordant on the topic of induction. The guidelines of the Society of Obstetricians and Gynaecologists of Canada do not recommend the induction of breech labor [14]. The Royal College of Obstetricians and Gynaecologists (UK) states that induction for breech presentation may be considered if individual circumstances are favorable [17]. Other guidelines like the German, French and US-American do not mention induction of labor for breech presentation at all [15, 16, 23]. On the other hand, induction of breech delivery is used in well-known centers all over Europe including Bergen, Frankfurt, Hamburg, Paris and Tel Aviv [7, 22, 24] (Louwen and Albrechtsen, personal communication). At Helsinki University Hospital induction of labor in breech presentation is performed for obstetric indications with the woman's consent, if all criteria for vaginal breech delivery are fulfilled.

The aim of this study was to assess the effectiveness of induction of labor in breech presentation at term and its maternal and neonatal safety.

\section{Materials and methods}

The study was a retrospective observational comparative study. It was performed at the Helsinki University Central Hospital in Finland with 10,500 deliveries annually. All breech deliveries from October 2011 to December 2013 were analyzed. The comparison was performed between all singleton, induced and spontaneous breech labors at term. Preterm deliveries, antepartum stillbirths, twin pregnancies, and fetuses with severe malformation were excluded from the study. Even though these groups were excluded from the study, induction of labor is a routine procedure at Helsinki Central University Hospital for preterm breech deliveries, antepartum stillbirths and twin pregnancies with either of the fetuses being in breech position if the criteria for the breech delivery are fulfilled and an induction is considered indicated. During the study two infants with severe malformation were born. The two infants with congenital heart defect underwent a spontaneous vaginal breech delivery with normal outcomes.

The criteria for vaginal breech delivery at Helsinki University Central Hospital are: (a) the mother is willing to deliver vaginally; (b) the woman's pelvic measurements are confirmed by magnetic-resonance pelvimetry, (conjugata vera $>11.5 \mathrm{~cm}$, interspinous diameter $>10 \mathrm{~cm}$ and intertuberous diameter $>10 \mathrm{~cm}$ ); (c) the estimated fetal weight is less than $4000 \mathrm{~g}$ evaluated by ultrasound; (d) the fetus is in frank, complete or incomplete breech position with the head in a flexed position; (e) the fetus does not suffer from an intrauterine growth restriction. An ultrasound examination is mandatory before delivery for determining fetal weight and the position of the fetal head and legs. All breech deliveries are always handled or guided by a consultant. The Løvset and Mauriceau Smellie Veit maneuvers are standard procedures for breech delivery at Helsinki University Central Hospital if manual assistance is needed during delivery.

The patient information including clinical and sociodemographic details was collected retrospectively from maternal and neonatal electronic records and from the hospital discharge registry including data regarding medical and obstetric history, indications of induction and the mode of delivery.

Induction of labor was defined as cervical ripening, an induction with oxytocin infusion or with amniotomy. For women with an unripe cervix (Bishop points <6) two methods of induction were used: labor was induced either with prostaglandin $\mathrm{E}_{1}$ if necessary in combination with oxytocin infusion or a balloon catheter was used in combination with oxytocin if necessary. An amniotomy was permitted for augmentation. For mothers with a ripe cervix (Bishop points $>6$ ) oxytocin induction was chosen alone or in combination with an amniotomy. The study received approval from the regional research committee of the medical faculty of Helsinki University.

Vaginal delivery rate was chosen as the primary outcome. Failure of induction of labor was defined as a secondary cesarean section during labor. Maternal, neonatal mortality and morbidity were chosen as secondary outcomes. Neonatal morbidity was defined as: (a) an umbilical arterial pH of <7.00; (b) an umbilical arterial base deficit of less than $-12 \mathrm{mmol} / \mathrm{L}$; (c) an admission to the neonatal intensive care unit for more than $24 \mathrm{~h}$; (d) low Apgar scores, defined as less than six at $5 \mathrm{~min}$; (e) a traumatic event during labor; (f) moderate or severe neonatal encephalopathy. The mortality rate of all breech deliveries was reviewed. Categorical variables were compared using the Chi-squared test. The Wilcoxon signed range test was used to compare continuous variables. A $P$ value of $<0.05$ was considered significant. All analysis was carried out using SAS 9.2. (SAS-Institute, Cary, USA). Good practice methods for retrospective database studies were considered [25]. The reporting of this study conforms to the STROBE statement.

\section{Results}

During the study period 24884 deliveries took place with 1082 fetuses in breech position. This resulted in a rate of $4.6 \%$. Out of all 1082 breech deliveries 792 were delivered at term. A total of 268 women met the inclusion 
Fig. 1 Study flowchart

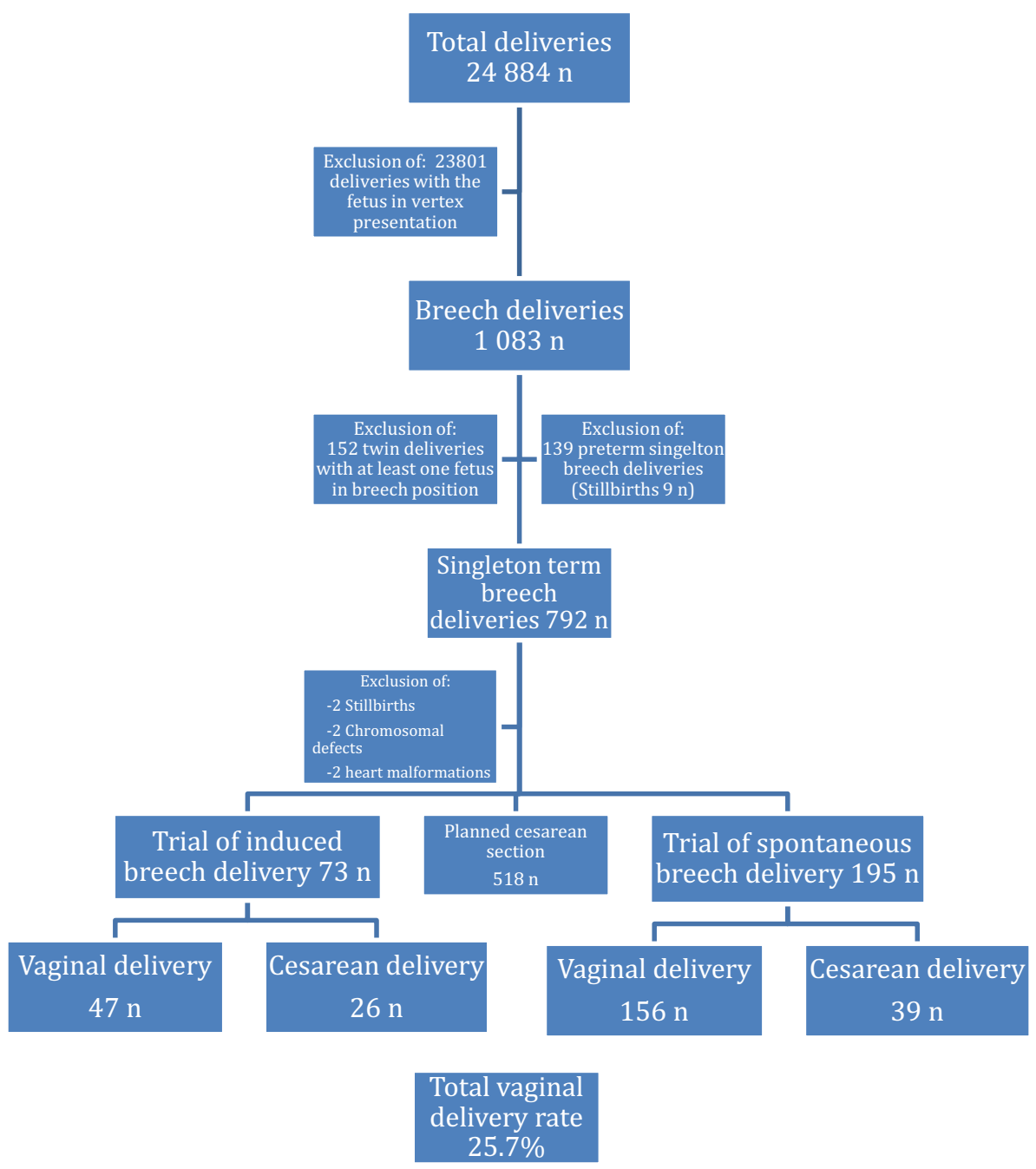

criteria of the study. In 73 cases the labor was induced, and in 195 cases the delivery started spontaneously and the remaining 518 women underwent an elective cesarean section (Fig. 1).

The indications for induction were diverse (Table 1). In the induction group 23 women were induced with prostaglandins, 28 women were induced with a balloon catheter, 16 women were induced with oxytocin infusion and six women underwent amniotomy. The mode of induction did not affect the success rate of the vaginal delivery. The women in the control group were comparable regarding their general characteristics (Table 2). The following significant differences between the two groups were observed: the second stage of labor was significantly longer in the induction group, there were more cases of diabetes in the induction group and the gestational age was higher in the induction group.

Table 3 shows the delivery, neonatal and maternal outcomes. In the induction group $64.4 \%$ of the women
Table 1 Fetal and maternal primary indications for induction

\begin{tabular}{lc}
\hline Indication & $n: 73$ \\
\hline Post-term pregnancy & 25 \\
Delayed delivery after spontaneous rupture of membranes & 24 \\
Pre-eclampsia & 10 \\
Diabetes & 3 \\
Other & 11 \\
\hline
\end{tabular}

delivered vaginally. The vaginal delivery rate in the spontaneous delivery group $(80 \%)$ was significantly higher $(p \leq 0.01)$ than in the induction group. Neonatal morbidity was rare in both groups, with no significant differences between the groups. Five infants were born with an umbilical artery $\mathrm{pH}$-rate of less than 7.00 in the spontaneous group $(2.6 \%)$, whereas none was born with low $\mathrm{pH}$ in the induction group. There were no infants with a cord-blood base deficit level of lower than -12 in the 
Table 2 Characteristics of women with induced vs. spontaneous breech delivery

\begin{tabular}{|c|c|c|c|c|c|}
\hline Variable & $\begin{array}{l}\text { Induced breech delivery } \\
73 n(n \text { or mean })\end{array}$ & $\%$ or range & $\begin{array}{l}\text { Spontaneous breech } \\
\text { delivery } 195 n \text { ( } n \text { or mean) }\end{array}$ & $\%$ or range & $P$ value \\
\hline Age (years) & $31.6(4.9)$ & $22-45$ & $32.2(4.3)$ & $20-43$ & 0.2313 \\
\hline Height (cm) & $169(5.6)$ & $158-180$ & $167.1(5.5)$ & $158-179$ & 0.09 \\
\hline Weight (kg) & $66.3(10.8)$ & $47-102$ & $63.5(10.4)$ & 44-99 & 0.09 \\
\hline BMI & $23.4(4.2)$ & $16-37$ & $22.7(3.6)$ & $18-37$ & 0.37 \\
\hline Gender (boy) & 25 & $34.2 \%$ & 83 & $42.6 \%$ & 0.22 \\
\hline Primiparity & 47 & $64.4 \%$ & 119 & $61 \%$ & 0.61 \\
\hline Smoking & 1 & $1.4 \%$ & 10 & $5.1 \%$ & 0.17 \\
\hline Gestational diabetes & 6 & $8.2 \%$ & 14 & $7.2 \%$ & 0.77 \\
\hline Hypertension & 8 & $11 \%$ & 7 & $3.6 \%$ & $<0.05$ \\
\hline Attempted cephalic version & 31 & $52.5 \%$ & 63 & $52 \%$ & 0.7 \\
\hline Previous cesarean section & 1 & $1.4 \%$ & 7 & $3.6 \%$ & 0.34 \\
\hline Gestational age (weeks at delivery) & $39.9(1.5)$ & $36-42$ & $39.6(1.1)$ & $37-42$ & $<0.05$ \\
\hline Gestational week $\geq 41$ & 26 & $36.1 \%$ & 23 & $11.8 \%$ & $<0.01$ \\
\hline Birth weight (g) & $3281(425)$ & $(2085-3980)$ & $3263(431)$ & $2406-4260$ & 0.35 \\
\hline Birth weight $(<2500 \mathrm{~g})$ & 5 & $6.9 \%$ & 4 & $2 \%$ & 0.07 \\
\hline Birth weight (2500-4000 g) & 68 & $91.1 \%$ & 188 & $97.4 \%$ & 0.3 \\
\hline Birth weight (>4000 g) & 0 & & 3 & $1.6 \%$ & \\
\hline Arterial umbilical $\mathrm{pH}$ & $7.2(0.1)$ & & $7.2(0.1)$ & & 0.8 \\
\hline II delivery stage (min) & $33.9(20.4)$ & $1-121$ & $17.9(16.2)$ & $1-91$ & $<0.01$ \\
\hline
\end{tabular}

Table 3 Neonatal and maternal outcome: induced breech vs. spontaneous delivery, adjusted for gestational age, parity, diabetes, neonatal birth weight and mothers height

\begin{tabular}{|c|c|c|c|c|c|}
\hline Variable & $\begin{array}{l}\text { Induced breech delivery } \\
73 n(n \text { or mean })\end{array}$ & $\%$ or range & $\begin{array}{l}\text { Spontaneous breech } \\
\text { delivery } 195 n \text { ( } n \text { or mean) }\end{array}$ & $\%$ or range & $P$ value \\
\hline Umbilical arterial $\mathrm{pH}<7.00$ & 0 & $0 \%$ & 5 & $2.6 \%$ & 0.17 \\
\hline Arterial cord-blood base deficit of $\leq-12$ & 0 & $0 \%$ & 7 & $3.6 \%$ & 0.1 \\
\hline Apgar score $<6$ at five min & 1 & $1.4 \%$ & 3 & $1.5 \%$ & 0.93 \\
\hline Neonatal unit admittance $>24 \mathrm{~h}$ & 3 & $4.1 \%$ & 5 & $2.6 \%$ & 0.68 \\
\hline $\begin{array}{l}\text { Metabolic acidosis } \\
(\mathrm{pH}<7.00 \text { and base deficit of } \leq-12)\end{array}$ & 0 & $0 \%$ & 1 & $0.5 \%$ & 0.36 \\
\hline Intrapartum stillbirths & 1 & $1.4 \%$ & 0 & $0 \%$ & \\
\hline Neonatal mortality & 0 & $0 \%$ & 0 & $0 \%$ & \\
\hline Arterial $\mathrm{pH}$ & 7.25 & $7.07-7.41$ & 7.25 & $7.00-7.48$ & 0.06 \\
\hline $\begin{array}{l}\text { Moderate or severe neonatal } \\
\text { encephalopathy }\end{array}$ & 0 & $0 \%$ & 0 & $0 \%$ & \\
\hline Birth trauma & 0 & $0 \%$ & 0 & $0 \%$ & \\
\hline Cesarean section & 26 & $35.6 \%$ & 39 & $20 \%$ & $<0.01$ \\
\hline Total blood loss (ml) & $539(361)$ & $150-2200$ & $557(421)$ & $150-2600$ & 0.42 \\
\hline Hospital stay post-partum (days) & $3(1.3)$ & $1-8$ & $3(1.1)$ & $1-6$ & 0.86 \\
\hline
\end{tabular}

Adjusted for birth weight, height of the mother, parity and gestational age

induction group compared to seven in the spontaneous delivery group. In the induction group one infant $(1.4 \%)$ received an Apgar score of less than six at $5 \mathrm{~min}$, while three infants in the spontaneous vaginal delivery group had an Apgar score of less than six at $5 \mathrm{~min}(1.5 \%)$ (Table 3 ).
Three infants in the induction group and four in the spontaneous group needed an admission to the neonatal intensive care unit for more than $24 \mathrm{~h}$. There were no cases of neonatal birth trauma or moderate or severe neonatal encephalopathy detected in either group. 
The overall stillbirth rate (antepartum and intrapartum) at Helsinki Central University Hospital during the study period for all pregnancies with the fetus in breech positions was $1.1 \%(N=12 / 1082)$. Stillbirth within this study was defined as a fetal death that occurred after 20 weeks of gestation. Only one stillbirth occurred intrapartum during the study period. The stillbirth rate for fetuses in cephalic presentation was $0.3 \%$ during the study period (data not shown) at the studied hospital. In preterm breech deliveries the rate was $6.4 \%$ with altogether nine cases being intrauterine stillbirths $(N=9 / 139)$. The mortality rate in all term breech deliveries was $0.4 \%(N=3 / 792)$ and $1.1 \%$ in all attempted vaginal breech deliveries at term $(N=3 / 270)$ at Helsinki Central University Hospital. The only intrapartum stillbirth at term occurred in the induction group. This results in an intrapartum mortality rate of $0.4 \%$ $(N=1 / 270)$. The mother had an induction of labor post term in week $41+0$. She delivered a stillborn baby during an emergency cesarean section in the first phase of labor. The fetus suffered from nuchal cord complications (Fig. 1).

Maternal outcomes were similar in post-partum bleeding, the length of hospital stay and in the occurrence of vaginal tears. Due to placenta accreta one emergency peripartum hysterectomy was performed in the spontaneous labor group. This woman had had a cesarean section in her previous pregnancy.

The total number of vaginal breech deliveries increased from 20.0 to $25.7 \%(N=203)$ during the study period due to induction of labor (Fig. 1).

\section{Conclusions}

The main finding of this study was that the vaginal delivery rate of $64 \%$ in induced labor with the fetus in breech presentation was significantly lower than the vaginal delivery rate in spontaneous breech deliveries $(80 \%)$ at term. The second stage of labor was significantly longer in induced than in spontaneous breech deliveries. The study also showed that induction of labor was not associated with an increased risk of neonatal morbidity. Overall, induction of breech delivery is a realistic option in carefully selected cases and significantly decreases cesarean section rates in this patient segment.

The higher cesarean section rate in the induction group was expected, as induction of labor was associated with an increased risk for secondary cesarean sections. The vaginal delivery rate after induction in breech position is comparable to the vaginal delivery rate for induced deliveries with the fetus in cephalic presentation as shown by a Cochrane review by Liu with a vaginal delivery rate of $73-74 \%$ [18]. It is also comparable with the vaginal delivery rates of $79.7 \%$ after successful cephalic version and induction of labor [26]. Induction of delivery with the fetus in vertex position is common practice [18], while induction in breech presentation is controversial [14-17]. It has been performed and reported rarely so far. During the last 35 years only three studies have addressed this topic in the English-language literature. These studies had small number of women $(N=13-53)$ and reported quite similar vaginal delivery rates ranging from 50 to $66 \%$. The induction groups in these studies were compared to spontaneous breech deliveries, cephalic deliveries or planned cesarean sections in breech position [20-22].

Neonatal mortality and morbidity were chosen as secondary outcomes. The results of this study show that neonatal adverse effects like umbilical arterial $\mathrm{pH}<7.00$; umbilical arterial base excess of more than $-12 ; 5$ min Apgar score $<6$; admission to the neonatal intensive care unit for more than $24 \mathrm{~h}$ and fetal mortality rate were similar for spontaneous and induced vaginal breech deliveries. These results confirm the findings of earlier breech induction studies, which did not show any significant differences in the rates of low Apgar score, asphyxia, birth trauma and maternal morbidity when compared to appropriate control groups [20-22].

There was no neonatal mortality in the study groups. However, the perinatal mortality rate in breech deliveries appears to be generally higher at different gestational age compared to the overall mortality rate of fetuses in cephalic presentation. The perinatal mortality rate is especially high for preterm breech deliveries. The higher rate cannot be explained by the higher rate of breech presentation in preterm fetuses only, as the prevalence of breech presentation during pregnancy starts decreasing from $33 \%$ at 20th week to 4-6\% at term [27]. Factors associated with an increased risk of poor fetal outcome are associated with fetal breech presentation [28] and include fetal growth retardation, fetal malformations, polyhydramnion, oligohydramnion, placenta praevia, and short umbilical cord [28, 29].

The study shows that the stillbirth rate of $1.1 \%$ in breech position is higher than the reported $0.3 \%$ stillbirth rate for fetuses in cephalic presentation. Breech presentation itself might be a risk factor for stillbirth. The stillbirth rate in breech deliveries at term was $0.4 \%$ in this study (3 out of 792 pregnancies). This rate is high compared to the overall risk of stillbirth at term [29]. The overall risk of stillbirth at term increases with gestational age from 2.1 per $10000(0.02 \%)$ in ongoing pregnancies at 37 weeks of gestation up to 10.8 per $10000(0.11 \%)$ in ongoing pregnancies at 42 weeks of gestation [30]. The intrapartum mortality rate was $1.4 \%$ in the induction group and $0.5 \%$ for all vaginally delivered neonates at term. The stillbirth was caused by multi-loop nuchal cord complication during the latent phase of the delivery. It was neither directly 
related to vaginal breech delivery nor to the induction itself. The intrapartum stillbirth could have been prevented with a more careful supervision or an elective cesarean section. The very same applies to most term and post-term stillbirths in cephalic presentation as well since most of them are theoretically preventable with an in-time elective cesarean section or induction of labor. The trend towards a higher stillbirth rate at term for fetuses in breech position might indicate that delaying delivery to term or post term could be especially detrimental for fetuses in breech presentation. An earlier induction might be reasonable, as fetuses in breech position seem to be at higher risk than fetuses in vertex position. The overall risk of stillbirth at term increases with gestational age from 2.1 per 10,000 ongoing pregnancies at 37 weeks of gestation up to 10.8 per 10,000 ongoing pregnancies at 42 weeks of gestation. At 38 weeks of gestation, the risk of expectant management carries a similar risk of fetal death as delivery, but after that the mortality risk related to expectant management is higher than the risk of delivery ( 39 weeks of gestation: 12.9 compared with 8.8 per 10,000; 40 weeks of gestation: 14.9 compared with 9.5 per 10,000; 41 weeks of gestation: 17.6 compared with 10.8 per 10,000$)$ [30]. The mortality rate of this study was comparable to the mortality rate found in previous breech labor studies (Vlemmix: $1.7 \%$; Goffinet: $0.08 \%$ and Hannah: $1.3 \%$ ) [6, 7, 31]. As expected, maternal morbidity was similar in both groups due to the selection criteria of patients for the study.

This study had some limitations: it did not have the statistical power to generalize data regarding the outcome of the infants. It can also be considered a limitation that the study was retrospective and not randomized. A randomized, prospective study is, however, difficult to set up due to the medical and ethical problems. The study group was small, although this study had the largest population in the literature written in English [20-22]. The low number of cases was due to the rarity of breech presentation combined with the fact that both the mother and the baby had to fit to several criteria for a safe vaginal delivery. One of the strengths of this study was that it was conducted at a single unit where clinical routines were uniform and the staff was experienced in handling breech deliveries.

The vaginal delivery rate in induced breech deliveries at term is similar to the reported rate of induced deliveries with the fetus in cephalic presentation, but lower than the delivery rate of spontaneous breech deliveries in the present study. External cephalic version is a known and safe possibility of primary prevention of cesarean section [32]. This study has shown that induction of labor might be an additional tool after unsuccessful external version to prevent primary cesarean section. The neonatal outcome after breech induction seems to be similar to that of spontaneous breech deliveries.
Acknowledgments The authors declare no source of funding.

\section{Compliance with ethical standards}

Conflict of interest The authors have no conflicts of interest. The authors state that they have full control of all primary data and they agree to allow the Journal to review their data if requested.

\section{References}

1. Healthcare Cost and Utilization Project (HCUP). August 2014. Agency for Healthcare Research and Quality, Rockville, MD. Available at: http://www.ahrq.gov/research/data/hcup/index.html

2. Declercq E, Barger M, Cabral HJ, Evans SR, Kotelchuck M, Simon C et al (2007) Maternal outcomes associated with planned primary cesarean births compared with planned vaginal births. Obstet Gynecol 109(3):669-677

3. Macharey G, Ulander VM, Kostev K, Vaisanen-Tommiska M, Ziller V (2014) Emergency peripartum hysterectomy and risk factors by mode of delivery and obstetric history: a 10-year review from Helsinki University Central Hospital. J Perinat Med

4. Louwen F, Leuchter LM, Reitter A (2012) Breech presentationmore than just caesarean vs. spontaneous birth. Z Geburtshilfe Neonatol 216(4):191-194

5. American College of Obstetricians and Gynecologists (the College) and the Society for Maternal-Fetal Medicine, Caughey AB, Cahill AG, Guise JM, Rouse DJ (2014) Safe prevention of the primary cesarean delivery. Am J Obstet Gynecol 210(3):179-193

6. Hannah ME, Hannah WJ, Hewson SA, Hodnett ED, Saigal S, Willan AR (2000) Planned caesarean section versus planned vaginal birth for breech presentation at term: a randomised multicentre trial. Term Breech Trial Collaborative Group. Lancet 356(9239):1375-1383

7. Goffinet F, Carayol M, Foidart JM, Alexander S, Uzan S, Subtil D et al (2006) Is planned vaginal delivery for breech presentation at term still an option? Results of an observational prospective survey in France and Belgium. Am J Obstet Gynecol 194(4):1002-1011

8. Haheim LL, Albrechtsen S, Berge LN, Bordahl PE, Egeland T, Henriksen $\mathrm{T}$ et al (2004) Breech birth at term: vaginal delivery or elective cesarean section? A systematic review of the literature by a Norwegian review team. Acta Obstet Gynecol Scand 83(2): $126-130$

9. Hellsten C, Lindqvist PG, Olofsson P (2003) Vaginal breech delivery: is it still an option? Eur J Obstet Gynecol Reprod Biol 111(2):122-128

10. Toivonen E, Palomaki O, Huhtala H, Uotila J (2012) Selective vaginal breech delivery at term-still an option. Acta Obstet Gynecol Scand 91(10):1177-1183

11. Ulander VM, Gissler M, Nuutila M, Ylikorkala O (2004) Are health expectations of term breech infants unrealistically high? Acta Obstet Gynecol Scand 83(2):180-186

12. Alarab M, Regan C, O'Connell MP, Keane DP, O'Herlihy C, Foley ME (2004) Singleton vaginal breech delivery at term: still a safe option. Obstet Gynecol 103(3):407-412

13. Bogner G, Strobl M, Schausberger C, Fischer T, Reisenberger K, Jacobs VR (2014) Breech delivery in the all fours position: a prospective observational comparative study with classic assistance. J Perinat Med

14. Kotaska A, Menticoglou S, Gagnon R, Farine D, Basso M, Bos H et al (2009) SOGC clinical practice guideline: vaginal delivery of breech presentation: no. 226, June 2009. Int J Gynaecol Obstet 107(2):169-176

15. Berger, R., J. Dudenhausen, A. Feige, W. Gonser, B.J. Hackelöer (federführend), H. Halle, M. Häusler, F. Kainer, M. Kühnert, 
KTM Schneider, K. Vetter, E. Weiss, J. Wisser (2006) Geburt bei Beckenendlage. Available at: http://www.agmfm-ev.de/_down load/unprotected/g_04_04_03_geburt_bei_beckenendlage.pdf

16. Carbonne B, Frydman R, Goffinet F, Pierre F, Subtil D (2001) Voie d'accouchement en cas de présentation du siège. Available at: http://www.cngof.asso.fr/D_PAGES/PURPC_08.HTM

17. Hofmeyr G. THE MANAGEMENT OF BREECH PRESENTATION. 2014; Available at: https://www.rcog.org.uk/globalassets/ documents/guidelines/gtg-no-20b-breech-presentation.pdf

18. Liu A, Lv J, Hu Y, Lang J, Ma L, Chen W (2014) Efficacy and safety of intravaginal misoprostol versus intracervical dinoprostone for labor induction at term: a systematic review and metaanalysis. J Obstet Gynaecol Res 40(4):897-906

19. Gissler M, Mohangoo AD, Blondel B, Chalmers J, Macfarlane A, Gaizauskiene A et al (2010) Perinatal health monitoring in Europe: results from the EURO-PERISTAT project. Inform Health Soc Care 35(2):64-79

20. O'Herlihy C (1981) Vaginal prostaglandin E2 gel and breech presentation. Eur J Obstet Gynecol Reprod Biol 11(5):299-303

21. Fait G, Daniel Y, Lessing JB, Bar-Am A, Gull I, Shenhav M et al (1998) Can labor with breech presentation be induced? Gynecol Obstet Invest 46(3):181-186

22. Rojansky N, Tsafrir A, Ophir E, Ezra Y (2001) Induction of labor in breech presentation. Int J Gynaecol Obstet 74(2):151-156

23. ACOG Committee Opinion (2006) Mode of term singleton breech delivery. Available at: http://www.acog.org/ResourcesAnd-Publications/Committee-Opinions/Committee-on-ObstetricPractice/Mode-of-Term-Singleton-Breech-Delivery

24. Kongress für Perinatale Medizin, editor. Geburtseinleitung bei Beckenendlage-durchaus eine Option-Ergebnisse über 5 Jahre aus einer deutschen Universitätsklinik. Z Geburtshilfe Neonatol
2011; 215 - FV02_02. doi:10.1055/s-0031-1293217; 1.-3. 12. 2011; Berlin: Thieme; 2011

25. Motheral B, Brooks J, Clark MA, Crown WH, Davey P, Hutchins D et al (2003) A checklist for retrospective database studiesreport of the ISPOR Task Force on Retrospective Databases. Value Health 6(2):90-97

26. Hants Y, Kabiri D, Elchalal U, Arbel-Alon S, Drukker L (2015) Induction of labor at term following external cephalic version in nulliparous women is associated with an increased risk of cesarean delivery. Archiv Gynecol Obstet 292(2):313-319

27. Franks Z, Nightingale R (2014) Decreased fetal movements: a practical approach in a primary care setting. Aust Fam Physician 43(11):782-785

28. Krebs L (2005) Breech at term. Early and late consequences of mode of delivery. Dan Med Bull 52(4):234-252

29. Luterkort M, Persson PH, Weldner BM (1984) Maternal and fetal factors in breech presentation. Obstet Gynecol 64(1):55-59

30. Rosenstein MG, Cheng YW, Snowden JM, Nicholson JM, Caughey AB (2012) Risk of stillbirth and infant death stratified by gestational age. Obstet Gynecol 120(1):76-82

31. Vlemmix F, Bergenhenegouwen L, Schaaf JM, Ensing S, Rosman AN, Ravelli AC et al (2014) Term breech deliveries in the Netherlands: did the increased cesarean rate affect neonatal outcome? A population-based cohort study. Acta Obstet Gynecol Scand 93(9):888-896

32. Reinhard J, Sänger N, Hanker L, Reichenbach L, Yuan J, Herrmann E, Louwen F (2013) Delivery mode and neonatal outcome after a trial of external cephalic version (ECV): a prospective trial of vaginal breech versus cephalic delivery. Archiv Gynecol Obstet 287(4):663-668 